\title{
The technique and scope of open-heart surgery
}

\author{
RAYMOND HURT \\ F.R.C.S. \\ Thoracic Surgeon, \\ North Middlesex Hospital, London, N.18
}

IN this paper the various methods of carrying out open-heart surgery are described, and the clinical results that are currently being obtained are reviewed.

\section{Technique of open-heart surgery}

An open-heart operation, which involves interrupting the pump action of the heart and, therefore, the supply of oxygenated blood to the brain and other vital organs, may be undertaken at normal body temperature, under hypothermic circulatory arrest (in which the patient is first cooled so that the oxygen requirements of the brain are reduced), or by heart-lung by-pass (in which a machine is used to take over the action of the heart and lungs).

\section{Normothermic circulatory arrest}

At $37^{\circ} \mathrm{C}$ the brain will suffer permanent damage if the blood supply is interrupted for more than 2 min. However, it is possible to operate on congenital pulmonary stenosis within this time limit and divide the three fused commissures of the pulmonary valve (Edwards, 1966). This technique is used in Liverpool, but most surgeons prefer to operate on this defect under the more leisurely conditions provided by cardio-pulmonary by-pass.

\section{Hypothermic circulatory arrest}

The body temperature may be reduced to $30^{\circ} \mathrm{C}$ (surface cooling) or to $12-15^{\circ} \mathrm{C}$ (profound hypothermia-Drew technique).

(a) Surface cooling. The nasopharyngeal temperature is lowered to $30^{\circ} \mathrm{C}$ by immersion of the anaesthetized patient in a bath of cold water. The circulation may then be arrested for 9 min with complete return of normal cerebral function after operation. This will provide sufficient time for the correction of certain congenital abnormalities such as the secundum type of atrial septal defect or pulmonary valve stenosis. Other abnormalities, such as ventricular septal defect, tetralogy of Fallot, primum type of atrial septal defect or aortic stenosis are more difficult to treat and re- quire a longer time for operation. They must be corrected by a different technique, either under profound hypothermia or with the use of a heartlung machine.

Mention must also be made of the use of hyperbaric oxygen. The dissolved oxygen content of the blood is increased by maintaining the patient and operating team in a pressure chamber of 2-3 atm of oxygen. This permits longer periods of arrested circulation at any given temperature and is of special value in very small infants, in whom the technical difficulties of cannulation of the heart are greater.

(b) Profound hypothermia (Drew technique). The body temperature is reduced to $12-15^{\circ} \mathrm{C}$ by blood-stream cooling with the use of a heato exchanger (Fig. 1). The patient's own lungs are? used for respiratory exchange and two pumps are utilized to take over the action of the right and left ventricles, which cease to provide an adequate output at a temperature of about $25^{\circ} \mathrm{C}$ due to the onset of ventricular fibrillation (in which case the output ceases altogether) or to extreme bradycardia. At a temperature of $12^{\circ} \mathrm{C}$ (nasopharyngeal, which approximates closely to that of the brain) (Hurt, 1963), the circulation may be interrupted for $90 \mathrm{~min}$ and this is sufficient for the correction of many types of intracardiac defect. If necessary, a further period of re-circulation will provide more time for the repair of the intracardiac defect. At this low temperature the heart has ceased to beat. There is no coronary circulation and the operation field is almost completely dry, producing operating conditions that are ideal. Since there is no artificial oxygenator, there is less damage to the blood than with the use of a heart-lung machine and consequently less post-operative bleeding.

At the Westminster Hospital (where the technique originated), at St Bartholomew's Hospital and in Bristol and Leeds, this method of openheart surgery has been found to give very satisfactory results. There are two important disadvantages to profound hypothermia-the time 


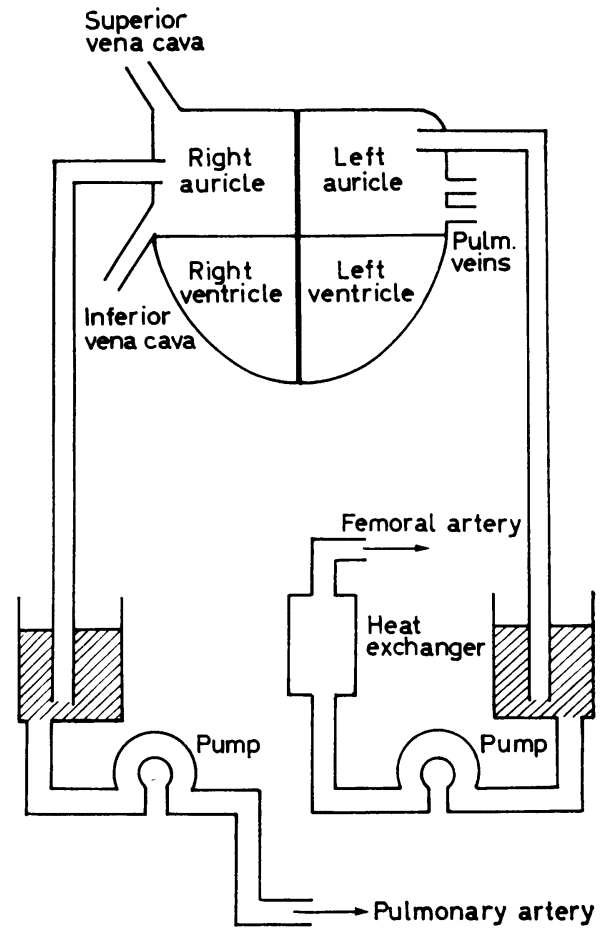

Fig. 1. The flow of blood during profound hypothermia. The blood is drawn off the right atrium into a reservoir, and is then pumped back into the lungs via a cannula introduced through the right ventricle into the pulmonary artery. The blood passes through the lungs into the left atrium, and is then drawn off into a reservoir. It is pumped through a heat-exchanger into a femoral artery, the cannula being directed proximally so that the blood flows through the aorta in a retrograde direction and then to the rest of the body.

limit allowed for the correction of the intracardiac abnormality, and the total length of operating time, which is increased by the periods of cooling and re-warming - and at St Bartholomew's Hospital this method of open-heart surgery has now been superceded by heart-lung by-pass with or without hypothermic arrest or electrical fibrillation of the heart. This technique has been found to be preferable for most cases of congenital and acquired heart disease, except tetralogy of Fallot (Tubbs, 1966, personal communication).

\section{Heart-lung by-pass}

Blood from the venae cavae flows by gravity into the heart-lung machine (Fig. 2). After oxygenation it passes through a heat-exchanger and back into the aorta via the femoral artery. The femoral artery cannula is directed proximally so that the blood flows through the aorta in a retrograde direction and then to the rest of the body. In some centres the blood is now returned through a cannula inserted directly into the aortic arch. The coronary blood flow draining via the coronary sinus into the heart is aspirated and returned to the heart-lung machine via a special pump. The patient may be cooled in order to reduce the oxygen requirements and, therefore, the flow of blood. This in turn reduces blood damage and consequent post-operative bleeding. If the temperature is reduced to $12^{\circ} \mathrm{C}$ the heartlung machine may be switched off for up to 90 $\mathrm{min}$, as in the Drew technique of profound hypothermia. This will also reduce the time of heartlung by-pass and, therefore, post-operative bleeding. In tetralogy of Fallot, in which there is a large bronchial blood supply to the lungs, this technique will also produce a much drier operation field.

In order to stop the heart beating and improve operating conditions the heart may be electrically fibrillated. This technique is used in pulmonary valvotomy or closure of a ventricular septal defect. Alternatively, as in operations on the mitral valve, ventricular fibrillation may be induced by cooling the heart and body to about $25^{\circ} \mathrm{C}$ by means of the

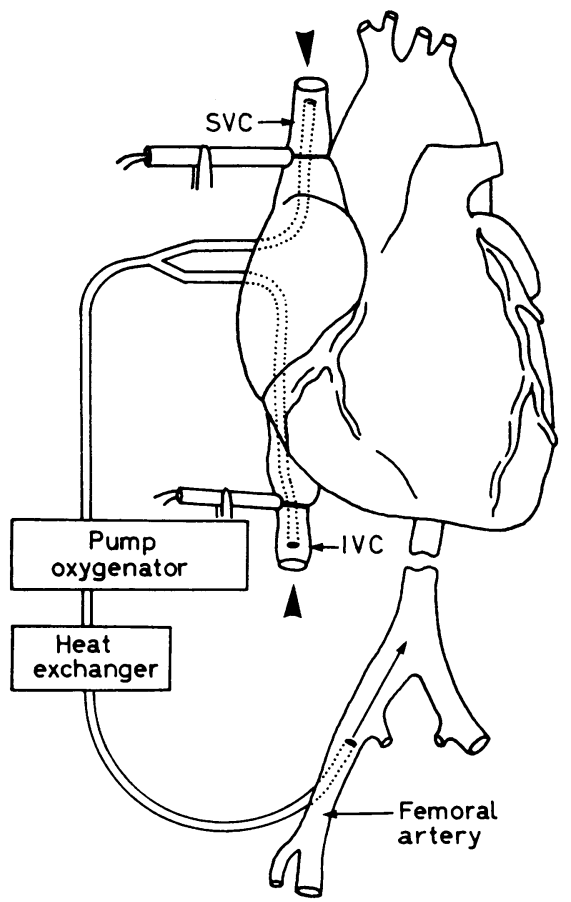

Fig. 2. The flow of blood during extracorporeal circulation. The blood flows by gravity from the superior and inferior vena cava into the pump oxygenator (heart-lung machine). After oxygenation, the blood is pumped via a heat-exchanger to a femoral artery. The femoral artery cannula is directed proximally so that the blood flows through the aorta in a retrograde direction and then to the rest of the body. 
heat-exchanger in the heart-lung machine. If the aortic valve is to be operated on, the aorta is cross-clamped above the origin of the coronary arteries. The myocardium must then be protected from the effects of anoxia and therefore special cannulae, which may be metal with bulbous tips or plastic with terminal balloons, are inserted into both coronary ostia for coronary perfusion. If desired, this blood may be cooled so as to reduce the heart temperature to about $10^{\circ} \mathrm{C}$ and induce hypothermic arrest. On the other hand, it is considered by some workers advantageous to allow the heart to continue to beat to permit better coronary perfusion. It is most important to prevent the occurrence of any distension of the left ventricle during perfusion, for otherwise damage to the lung may occur due to a rise in left atrial pressure and this is very likely to lead to postoperative respiratory insufficiency. To prevent this distension occuring it is necessary to vent the left ventricle by inserting a catheter into its apex and allowing any excess blood to siphon back into the heart-lung machine. This vent is especially important in cases of aortic incompetence. In operations on the aortic valve when the aorta has been opened, gentle suction may be applied to the catheter so as to keep the operation field dry.
The catheter is also useful when the heart is being finally closed in order to expel any residual air which may have become trapped in the left ventricle.

\section{Types of heart-lung machine}

An artificial heart-lung machine consists essentially of an oxygenator and a pump. Venous blood from the inferior and superior vena cava enters the oxygenator where the oxygen and carbon dioxide exchange occurs, and the pump then returns the oxygenated blood into the aorta. The mode of oygenation determines the main difference between the various types of heart-lung machine (Fig. 3).

\section{Film oxygenator}

There are two main types of film oxygenator. In one the blood is spread out over a series of stainless steel mesh screens (Mayo-Gibbon machine) and in the other it is spread over a series of rotating stainless steel discs (Melrose or Ross machine). In the Melrose machine the drum and discs both rotate, whereas in the Ross machine only the discs are moving. The latter arrangement is preferable for there is less blood damage. Disc oxygenators have been used extensively in this country and have been found to be satisfactory for periods of up to $4 \mathrm{hr}$.

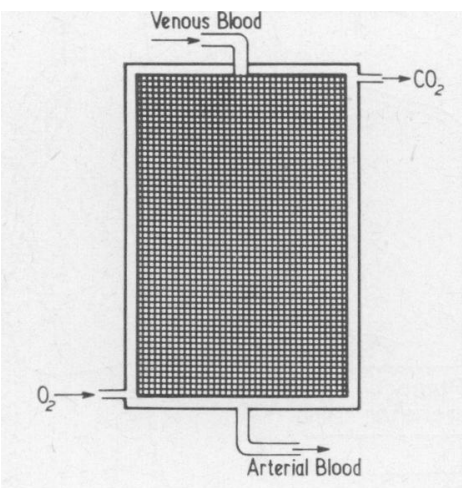

(a)

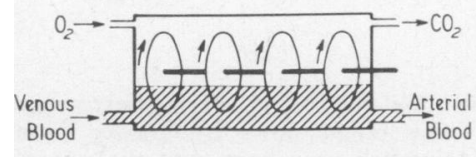

(c)

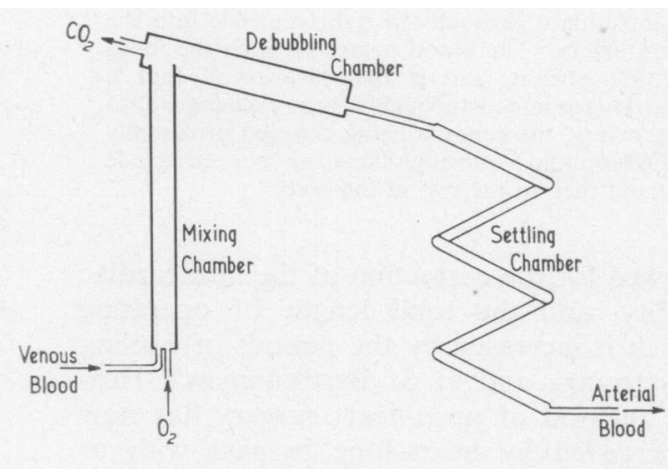

(b)

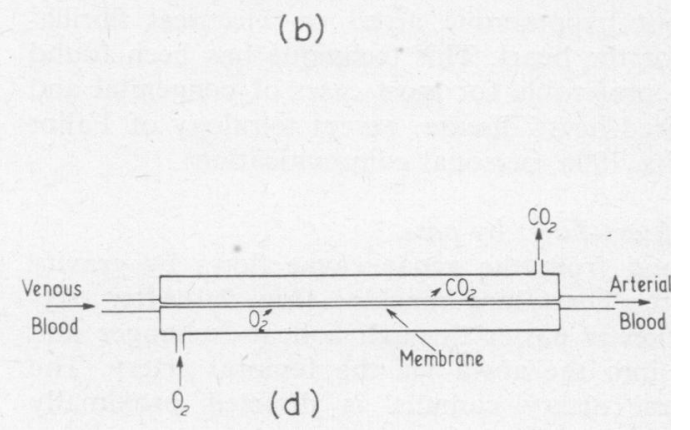

FIG. 3. Types of heart-lung machine. (a) and (c) film oxygenators; (a) stationary screen type; (c) rotating disc type; (b) bubble oxygenator; (d) membrane oxygenator. 


\section{Bubble oxygenator}

Oxygen is bubbled through a column of blood and the resulting foam then passes through debubbling and settling chambers so as to render the blood completely bubble-free. This principle has been used in the Baxter and Rygg bags (Fig. 4). These are disposable plastic oxygenators which

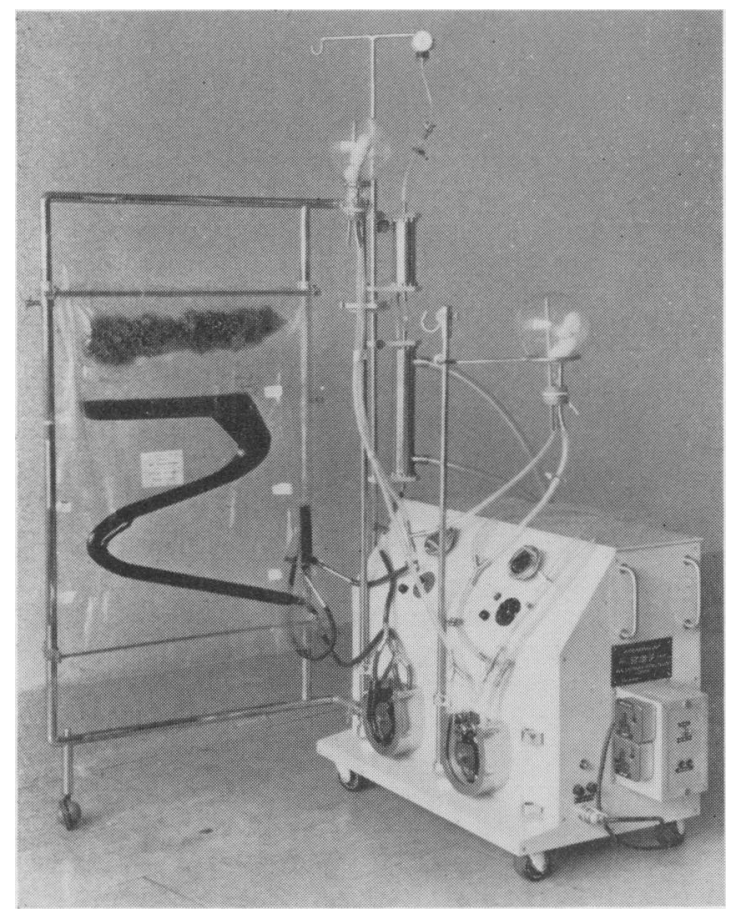

FIG. 4. Disposable bubble oxygenator (Baxter bag). The pump on the left returns the oxygenated blood from the Baxter bag to the patient, and the pump on the right removes the coronary sinus blood from inside the heart and returns it to the heart-lung machine.

have proved to be extremely efficient and satisfactory, and contrary to expectation only cause a minimal amount of blood damage.. They are satisfactory for perfusions lasting up to $3 \mathrm{hr}$.

\section{Membrane oxygenator}

This oxygenator imitates the lungs more closely than does any other oxygenator and the blood passes over an exceedingly thin plastic membrane, through which oxygen and carbon dioxide diffuse. Until recently it has not been possible to produce this type of oxygenator with a sufficiently large output of oxygenated blood, but Bramson et al. (1965) have now reported from San Francisco the clinical use of such a machine. This type of oxygenator is now available in this country.

\section{Clinical results}

\section{Acquired heart disease}

Aortic valve. Until the advent of valve substitutes and valve grafts, it had only been possible to operate on the aortic valve if it was stenosed and not incompetent. The operation was carried out as a blind operation, using a dilating instrument introduced through the left ventricle to split the calcified commissures between the valve cusps. The results of this operation were far from satisfactory, due either to inadequate relief of the stenosis, or from the production of severe incompetence. A later development was the introduction of valvoplasty, in which the calcified material was removed from the valve cusps at an open operation under cardio-pulmonary by-pass. This technique gave good immediate results, but subsequent restenosis occurred in a large proportion of cases (Hurley et al., 1967).

The stenosed or incompetent aortic valve may now be satisfactorily replaced by an artificial valve, of which the Starr valve (Fig. 5) is the type most commonly employed. This American valve consists of a silicone rubber ball enclosed in a vitallium alloy cage. The ring of the cage is covered with a knitted Teflon sleeve which is sutured to the aortic wall at the site of the excised valve. Many other types of artificial valve have been designed, including one by Melrose at the Royal Postgraduate Medical School. The immediate results of valve replacement with these artificial valves are very good, even in relatively poor-risk patients. Starr has replaced 218 aortic valves between 1961 and 1966, and 169 patients (77\%) were alive and well at a recent follow-up (Starr, 1966). These patients must all be maintained on long-term anticoagulant therapy, however, for the risk of embolic complications is as much as $36 \%$. The incidence is much greater within the first 2 years of operation. Recently an anti-thrombotic factor has been incorporated in the valve in order to try to prevent clot formation.

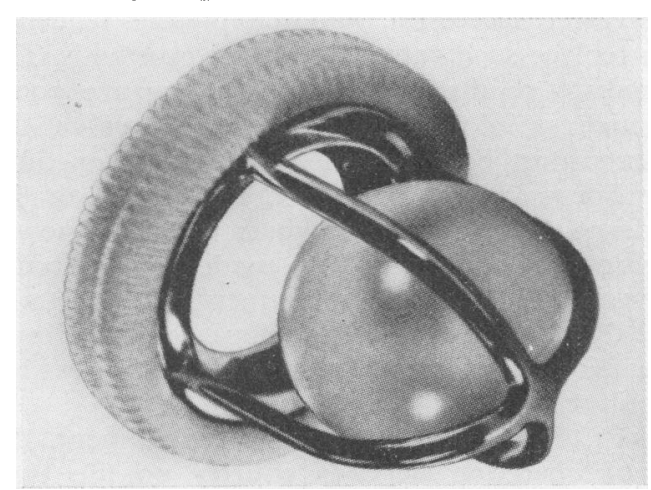

FIG. 5. Starr valve. 
Valve homografts have been used during the last 5 years by Ross in England and BarrattBoyes in New Zealand, and valve heterografts by Gunning and Binet in England and France. They are technically more difficult to insert than artificial valves, but there has been a complete absence of thrombo-embolic complications. No anticoagulants are required after operation and it seems possible that in the future they will be used in preference to artificial valves. Ross $(1964,1966)$ has carried out 181 aortic homograft operations, with a $6 \%$ mortality in the last fifty cases, and Barratt-Boyes et al. (1965) 101 operations also with a $6 \%$ mortality. In some cases of aortic incompetence the valve ring is grossly enlarged and it has been found difficult to obtain a homograft of suitable size. It is in these cases, and also at surgical centres where there has been difficulty in obtaining a supply of homografts, that Binet (1965) has found heterografts to be useful.

Mitral valve. Mitral stenosis is the most common intracardiac lesion requiring surgery. It is generally treated by closed valvotomy carried out by introducing a dilating instrument through the left ventricle. The functional results of this operation are very good and the risk is relatively small in the uncomplicated case but there is a tendency in America to carry out these operations under direct vision with heart-lung by-pass, so that if a satisfactory result is not obtained the valve may be replaced. A valve replacement will also be required in cases of mitral stenosis, whether or not a closed valvotomy has been attempted, if there is associated incompetence or severe calcification, or if a poor functional result has been obtained at a previous valvotomy.

Mitral incompetence can only be treated by an open-heart operation. In cases in which the valve ring is dilated and the valve cusps themselves are relatively normal, attempts at plication of the valve ring (Wooler, 1966, personal communication), or the insertion of Teflon buttresses, have only been moderately successful, and the present tendency is to replace such valves by a Starr prosthesis. The immediate results of these operations are good, although as in the case of the aortic valve, the patients must be maintained indefinitely on anticoagulants, and the long-term results due to the incidence of embolic phenomena are not known. Attempts have recently been made to use homografts for mitral valve replacement, but the technical difficulties of their insertion are greater and it remains to be seen whether this is a feasible procedure.

As in the case of aortic valve replacement, the risk of operation depends entirely on the type of case being operated on, whether or not there is associated aortic or tricuspid valve disease and whether the pulmonary vascular resistance indicating associated lung changes is raised. Starr has reported 139 mitral valve replacements carried out since 1960, of whom $72 \%$ were alive 6 years later.

In cases in which both the mitral and aortic valves are severely damaged, Starr has carried out double valve replacement in 110 patients, with a $15 \%$ operative mortality and a $75 \%$ survival rate.

\section{Congenital heart disease}

The majority of congenital heart defects may now be corrected and this field of surgery has provided endless scope for surgical ingenuity. It is, of course, a numerically smaller group of patients than those with acquired heart disease.

Atrial and ventricular septal defects. It is now generally accepted that an atrial or ventricular septal defect should be closed if the left-to-right shunt is greater than $2: 1$, for the risk is small and the operative results good. Atrial septal defects are increasingly being closed under cardiopulmonary by-pass rather than the less elaborate technique of surface cooling, but if there is associated mitral incompetence (primum type of atrial septal defect) then the former method is obligatory, in order to repair the cleft in the mitral valve cusp. Ventricular septal defects are closed under cardio-pulmonary by-pass or profound hypothermia. If the shunt is so large as to cause pulmonary hypertension and the child is under the age of 3-4 years and is therefore too young to undergo an open-heart operation with safety, then the main pulmonary artery may be constricted by a floss silk or tape ligature ('banding' operation) in order to reduce the pulmonary blood flow until the child is old enough to have the septal defect closed under cardio-pulmonary by-pass.

Tetralogy of Fallot. A complete correction of the two main abnormalities associated with tetralogy of Fallot (ventricular septal defect and obstruction to the outflow tract of the right ventricle, which may be due to hypertrophied infundibular muscle and/or stenosis of the pulmonary valve itself) may be carried out under cardiopulmonary by-pass or profound hypothermia. It is difficult to assess accurately the risk of this operation, for the interpretation of results by various authors is not easy, partly because of a different proportion of cyanotic and acyanotic patients in different reported series, and partly because of the improvements in technique in recent years. It is probably fair to say that the mortality ranges from $5 \%$ for acyanotic cases to as much as $30 \%$ for severely cyanotic cases (Bahnson et al., 1962; Gerbode et al., 1964 ; Hallman et al., 1963 ; Kirklin et al., 1965 ; Lillehei et al., 1964). 
In some cases of tetralogy of Fallot the pulmonary artery is too underdeveloped to receive the full flow of blood from the right ventricle, and in these cases it may be necessary to carry out the operation in two stages, relieving the pulmonary stenosis at the first operation by resecting the hypertrophied infundibular muscle and incising, if necessary, the stenosed pulmonary valve, and then subsequently, when the pulmonary arterial system has enlarged, closing the ventricular septal defect. In other cases, the child is too severely disabled or too small to undergo an openheart operation, and in these cases it is preferable to carry out a Blalock or Potts anastomosis operation (preferably the former) in order to bring partially oxygenated systemic blood to the lungs for further oxygenation. This will reduce the cyanosis and therefore the disability until the child is old enough to undergo a complete correction. Alternatively a closed pulmonary valvotomy may be carried out (Taylor et al., 1963).

Pulmonary stenosis. In this condition there is stenosis of the pulmonary valve itself and often also hypertrophy of the muscle of the outflow tract (infundibulum) of the right ventricle.

The results of surgery in this condition are good. The pulmonary valvotomy is best carried out through the pulmonary artery under cardiopulmonary by-pass. The commissures are separated from the pulmonary artery and are then carefully incised, though care must be taken not to separate the cusps too much, or incompetence will occur. Even though there is associated hypertrophy of the muscle of the right ventricle causing infundibular stenosis, there is no need to carry out an infundibular resection, unless the hypertrophy is severe (Braimbridge et al., 1966).

Transposition of the great vessels. Transposition of the great vessels is the commonest cardiac cause of cyanosis from birth and few infants survive more than 1 year. Since the aorta arises from the right ventricle and the pulmonary artery from the left ventricle, the systemic and pulmonary circulations are to a very great extent functionally separate. However, for survival there must be some mixing of the two circulations and this is usually through an atrial septal defect, ventricular septal defect or patent ductus arteriosus. In order to increase this shunt, an artificial atrial septal defect may be created (Blalock \& Hanlon, 1950). By using special clamps, this operation may be performed in infancy without the use of a heartlung machine. At Great Ormond Street Children's Hospital 120 patients have been operated on between 1959 and 1965 . The survival rate was $42 \%$ and in 1964 was 69\% (Aberdeen, 1966, personal communication). A recent development has been the creation of an atrial septal defect by a balloon catheter (Watson \& Rashkind, 1967). This is carried out under local anaesthesia under radiographic control and the results appear to be good. Since the risk is considerably less than the BlalockHanlon operation, this technique is now the procedure of choice for this condition.

At a later date a definitive 'total correction' of the abnormality may be carried out under heart-lung by-pass (Mustard et al., 1964). A new inter-atrial channel is constructed with a pericardial graft to direct the oxygenated blood from the left atrial orifices of the pulmonary veins to the tricuspid valve and thence aorta.

Total anomalous pulmonary veins. Total anomalous pulmonary venous drainage is relatively uncommon, but infants with this condition seldom survive beyond the first year of life. Since the whole of the pulmonary return is to the right atrium, often via an abnormal chamber, an atrial septal defect must be present for survival. The deformity may be corrected under cardio-pulmonary by-pass by redirecting the pulmonary blood to the left atrium and closing the septal defect (Ochsner et al., 1962).

\section{References}

Bahnson, H.T., Spencer, F.C., LandtMan, B., Wolf, M.D., Neill, C.A. \& Taussig, H.B. (1962) Surgical treatment and follow-up of 147 cases of tetralogy of Fallot treated by correction. J. thorac. cardiovasc. Surg. 44, 419.

BARRATt-Boyes, B.G. (1964) Homograft aortic valve replacement in aortic incompetence and stenosis. Thorax, $19,131$.

Barratt-Boyes, B.G., Lowe, J.B., Cole, D.S. \& Kelly, D.T. (1965) Homograft valve replacement for aortic valve disease. Thorax, 20, 495.

BINET, J.P. (1965) Heterologous aortic valve transplantation. Lancet, ii, 1275.

Blalock, A. \& Hanlon, C.R. (1950) Surgical treatment of complete transposition of aorta and pulmonary artery. Surg. Gynec. Obstet. 90, 1.

Braimbridge, M.V., OAKLey, C.M., Bentall, H.H. \& Cleland, W.P. (1966) Pulmonary valve stenosis without ventricular septal defect: Results of surgery. Thorax, 21, 164.

Bramson, M.L., Osborn, J.J., Main, F.B., O'Brien, M.F., Wright, J.S. \& Gerbode, F. (1965) A new disposable membrane oxygenator with integral heat exchange. J. thorac. cardiovasc. Surg. 50, 391.

EDWARDS, F.R. (1966) Foundations of Thoracic Surgery, p. 93. Livingstone, Edinburgh.

Gerbode, F., Kerth, W.J., Sabar, E.F., Selzer, A. \& OsBORN, J.J. (1964) The operative treatment of congenital heart lesions in adults. J. thorac. cardiovasc. Surg. 48, 601.

Hallman, G.L. \& Cooley, D.A. (1963) Surgical treatment of tetralogy of Fallot. J. thorac. cardiovasc. Surg. 46, 419.

Hurley, P.J., Lowe, J.B. \& Barratt-Boyes, B.G. (1967) Debridement-valvotomy for aortic stenosis in adults: a follow-up of 76 patients. Thorax, 22, 314 .

HURT, R.L. (1963) Profound hypothermia. St Barts Hosp. J. Suppl. October. 
Kirklin, J.W., Wallace, R.B., McGoon, D.C. \& Dushane, J.W. (1965) Early and late results after intrecardiac repair of tetralogy of Fallot. Ann. Surg. 162, 578.

Lillehei, C.W., Levy, M.J., Adams, P. \& Anderson, R.C. (1964) Corrective surgery for tetralogy of Fallot. $J$. thorac. cardiovasc. Surg. 48, 556.

Mustard, W.T., Keith, J.D., Trusler, G.A., Fowler, R. \& KIDD, L. (1964) Surgical management of transposition of the great vessels. J. thorac. cardiovasc. Surg. 48, 953.

Ochsner, J.L., Cooley, D.A., McNamara, D.G. \& Kilne, A. (1962) Surgical treatment of cardiovascular anomalies in 300 infants younger than one year of age. $J$. thorac. Surg. 43, 182.
Ross, D.N. (1964) Homotransplantation of the aortic valve in the subcoronary position. J. thorac. cardiovasc. Surg. 47, 713.

Ross, D.N. (1966) International Medical Tribune of Great Britain, 30th June.

STARR, A. (1966) International Medical Tribune of Great Britain, 30th June.

TAYlor, D.G., Thornton, J.A., Grainger, R.G. \& Verel, D. (1963) Closed pulmonary valvotomy for the relief of Fallot's tetralogy in infancy. $J$. thorac. cardiovasc. Surg. 46, 77.

WATSON, H. \& RASHKIND, W.J. (1967) Creation of atrial septal defects by balloon catheter in babies with transposition of the great arteries. Lancet, i, 403.

\title{
Respiratory failure and acid-base status in hypothermia
}

\author{
M. W. MCNICOL \\ M.B., M.R.C.P.
}

\author{
Central Middlesex Hospital, London, N.W.10
}

RESPIRATORY failure is best defined in terms of deviation of arterial blood gas tensions outwith a 'normal' range (Campbell, 1965), commonly by a carbon dioxide tension greater than $50 \mathrm{mmHg}$ and an oxygen tension less than $60 \mathrm{mmHg}$. In hypothermia the first problem is in defining the "normal' values. This difficulty stems from the fact that normal man does not become hypothermic; the response of patients made hypothermic under anaesthesia reflects anaesthetic techniques almost entirely, and the findings in patients with accidental hypothermia are usually complicated by intercurrent acute respiratory infection. The changes in hibernating or poikilothermic animals provide some indication of what the normal pattern may be (Rahn, 1967 ; Robin, 1962 ; Lyman \& Hastings, 1951), but these are not entirely applicable to man. The problems in definition are further complicated by changes in blood gas tensions and $\mathrm{pH}$ due to the physical effects of change in temperature.

It is likely that accidental hypothermia is frequently complicated by respiratory failure. McNicol \& Smith (1964) found evidence of respiratory failure in four of the eight patients they studied. The hypoxaemia of respiratory failure may be an important factor in the high mortality. Acid-base disturbance is also common, the acidosis of carbon dioxide retention being found in some patients and in others metabolic acidosis associated with fall in plasma bicarbonate probably due to tissue hypoxia from a combination of arterial hypoxaemia and impaired peripheral circulation (Jones et al., 1966). I wish to discuss first the problems of diagnosis of respiratory failure and acid-base disturbance in the hypothermic patient and then to consider the ways in which these disturbances may be produced by hypothermia.

Diagnosis of respiratory failure and assessment of acid-base status in the hypothermic patient

With fall in temperature the solubility of gases increases; a liquid at a lower temperature con? tains the same quantity of gas at a lower pressure. In blood, with fall in temperature the effects produced by change in the dissociation constant of buffers and displacement to the left of the haemoglobin dissociation curve are added to increased gas solubility. In an anaerobically cooled sample of blood the carbon dioxide content of which is constant, carbon dioxide tension falls, plasma bicarbonate rises slightly and there is a marked rise in $\mathrm{pH}$. Oxygen tension falls, but oxygen saturation shows no change. The changes in carbon dioxide tension and $\mathrm{pH}$ produced in this fashion probably provide the best model for the 'normal' changes in hypothermia (Brewin et al., 1955), but the changes for oxygen do not (see below).

If the normal levels of carbon dioxide tension and $\mathrm{pH}$ in the hypothermic patient are defined by an anaerobically cooled blood sample, assessment of carbon dioxide tension and $\mathrm{pH}$ are greatly simplified, for a blood sample from the patient measured in an electrode working at its normal temperature $\left(37\right.$ or $\left.38^{\circ} \mathrm{C}\right)$ is anaerobically warmed and normality is then defined by normal ranges at electrode working temperature. This seems to remain the most useful method of assessment of acid-base and carbon dioxide tension (Patterson 